\title{
Penentuan Indeks Seleksi untuk Galur Dihaploid Padi Sawah Tadah Hujan Berdaya Hasil Tinggi
}

\author{
Determination of Selection Index for High Yielding Doubled Haploid Rainfed Rice Lines
}

\author{
Miftahur Rizqi Akbar ${ }^{1}$, Bambang Sapta Purwoko ${ }^{2 *}$, Iswari Saraswati Dewi ${ }^{3}$, \\ Willy Bayuardi Suwarno ${ }^{2}$, dan Sugiyanta ${ }^{2}$
}

\begin{abstract}
${ }^{1}$ Program Studi Pemuliaan dan Bioteknologi Tanaman, Sekolah Pascasarjana, Institut Pertanian Bogor
${ }^{2}$ Departemen Agronomi dan Hortikultura, Fakultas Pertanian, Institut Pertanian Bogor

(Bogor Agricultural University), Jl. Meranti, Kampus IPB Darmaga, Bogor 16680, Indonesia

${ }^{3}$ Balai Besar Bioteknologi dan Sumber Daya Genetika Pertanian

Jl. Tentara Pelajar, No. 3A, Cimanggu, Bogor 16111, Indonesia
\end{abstract}

Diterima 31 Januari 2019/Disetujui 25 Juni 2019

\begin{abstract}
Rainfed rice breeding for high yield is an alternative to increase national rice production. The breeding can be accelerated using anther culture technique. The selection of high productivity lines may be more effective if it also involves the traits contributing to or affecting the yield traits. This study aimed at determining suitable characters as selection criteria and obtain a selection index model for high yielding doubled haploid rainfed rice lines. The experiment was conducted in a greenhouse of ICABOGRAD, Bogor and Sawah Baru Experimental Station, Bogor Agricultural University using a randomized complete block design (RCBD) with three replications. Thirty doubled haploid lines derived from anther culture and two check varieties namely Ciherang and Inpari 18 were used. The results showed that plant height (TT), number of filled grain per panicle (GI), and productivity (PRD) could be used as suitable selection characters. The determination of selection index obtained a selection model which was Selection index $=0.48$ PRD +0.31 JGI - 0.31 TT. This model can be used to select high yielding doubled haploid rainfed rice lines.
\end{abstract}

Keywords: anther culture, genetic variability, selection criteria, yield potential

\section{ABSTRAK}

Perakitan padi sawah tadah hujan yang berdaya hasil tinggi merupakan alternatif untuk meningkatkan produksi padi nasional. Perakitan tersebut dapat dipercepat menggunakan teknik kultur antera. Penggunaan karakter-karakter yang berkontribusi atau mempengaruhi daya hasil dapat meningkatkan efisiensi seleksi untuk memperoleh galur-galur yang berdaya hasil tinggi. Tujuan penelitian ini ialah untuk menentukan karakter seleksi yang tepat dan memperoleh indeks seleksi untuk mendapatkan galur dihaploid padi sawah tadah hujan berdaya hasil tinggi. Penelitian dilakukan di rumah kaca BB Biogen, Bogor dan Kebun Percobaan Sawah Baru, Institut Pertanian Bogor, menggunakan rancangan kelompok lengkap teracak (RKLT) dengan 3 ulangan. Perlakuan yang digunakan adalah 30 galur dihaploid dan 2 varietas pembanding yaitu Ciherang dan Inpari 18. Hasil menunjukan bahwa karakter tinggi tanaman (TT), jumlah gabah isi per malai (GI), dan produktivitas (PRD) dapat dijadikan sebagai karakter seleksi yang tepat. Penentuan indeks seleksi diperoleh suatu model seleksi yaitu Indeks seleksi $=0.48$ PRD +0.31 GI - 0.31 TT. Model tersebut dapat digunakan untuk menyeleksi galur-galur dihaploid padi sawah tadah hujan yang berdaya hasil tinggi.

Kata kunci: daya hasil, keragaman genetik, kriteria seleksi, kultur antera

\section{PENDAHULUAN}

Padi merupakan salah satu makanan pokok terpenting kedua di dunia setelah tanaman gandum. Produksi padi Indonesia sebesar 56.5 juta ton gabah kering giling (GKG)

\footnotetext{
* Penulis untuk korespondensi. e-mail: bspurwoko@apps.ipb. ac.id
}

pada tahun 2018 (BPS, 2018). Produktivitas padi pada lahan tadah hujan yang berkisar antara 3.0-4.0 ton $\mathrm{ha}^{-1}$ masih kalah jika dibandingkan dengan produksi padi sawah irigasi yang berkisar antara 4.5-6 ton ha ${ }^{-1}$ (Susanto et al., 2017). Lahan sawah tadah hujan sebesar 3.4 juta hektar berpotensi menjadi alternatif untuk meningkatkan produksi beras nasional (Kementan, 2018). Oleh karena itu perakitan padi sawah tadah hujan yang memiliki daya hasil tinggi sangat penting. 
Perakitan padi sawah tadah hujan berdaya hasil tinggi dapat dilakukan dengan teknik kultur antera padi. Pemanfaatan kultur antera dapat meningkatkan efisiensi proses seleksi, menghemat biaya, waktu, dan tenaga kerja (Dewi dan Purwoko, 2012). Galur dihaploid yang bersifat homozigos dapat diperoleh pada satu generasi (Purwoko et al., 2010). Kultur antera dimanfaatkan untuk mendapatkan padi gogo dengan sifat-sifat tipe baru (Safitri et al., 2010) dan padi sawah tadah hujan toleran kekeringan (Gunarsih et al., 2016; Akbar et al., 2018a).

Seleksi dilakukan sesuai dengan tujuan yang diinginkan dalam perakitan varietas. Parameter yang dapat digunakan untuk penentuan kriteria seleksi adalah nilai heritabilitas, ragam genetik, ragam fenotipe, dan koefisien keragaman genetik (KKG) (Yunianti et al., 2010). Seleksi dapat dilakukan secara langsung terhadap karakter utama dan tidak langsung menggunakan karakter sekunder yang berkorelasi dengan karakter utama. Karakter daya hasil merupakan karakter utama dalam perakitan padi sawah tadah hujan. Seleksi secara langsung pada karakter daya hasil merupakan metode yang mudah dilakukan. Akan tetapi, karakter ini merupakan karakter kuantitatif yang dikendalikan oleh banyak gen sehingga mekanismenya sangat kompleks (Islam et al., 2017). Lingkungan juga memiliki pengaruh yang besar terhadap karakter daya hasil. Penggunaan karakter sekunder penunjang produksi menjadi sangat penting. Akan tetapi, pemilihan karakter tersebut harus memiliki kriteria yaitu nilai heritabilitas yang tinggi dan memiliki korelasi yang signifikan dengan karakter produksi. Pendugaan suatu karakter penting dalam suatu populasi yang berbeda menjadi sangat penting karena setiap populasi memiliki keragaman yang berbeda-beda.

Analisis multivariat merupakan analisis yang digunakan untuk menyederhanakan data yang kompleks (Janmohammadi et al., 2014). Analisis multivariat digunakan untuk menentukan karakter penting dari suatu tanaman. Analisis multivariat terdiri atas analisis komponen utama, analisis klaster, dan analisis diskriminan. Analisis komponen utama (principal component analysis) adalah teknik analisis multivariat untuk menganalisis data kuantitatif yang saling berhubungan. Analisis ini bertujuan untuk mendapatkan informasi penting, menggambarkan set variabel ortogonal yang dinamakan komponen utama, dan menampilkan pola kemiripan karakter yang diobservasi sebagai titik pada gambar (Abdi dan Williams, 2010; Nachimuthu et al., 2014). Tujuan penelitian ini ialah untuk menentukan karakter seleksi yang tepat dan memperoleh indeks seleksi untuk mendapatkan galur berdaya hasil tinggi.

\section{BAHAN DAN METODE}

Penelitian dilakukan mulai September 2016 sampai Februari 2017. Penyemaian dilaksanakan di rumah kaca BB Biogen, Bogor dan penanaman di Kebun Percobaan Sawah Baru, Institut Pertanian Bogor, pada titik koordinat 6 33'47.9'S, 106 44'10.8'E. Curah hujan pada percobaan ini rata-rata $249.78 \mathrm{~mm}$ dengan suhu rata-rata sebesar $26^{\circ} \mathrm{C}$. Materi genetik yang digunakan adalah 30 galur dihaploid (DH1) dan 2 varietas pembanding yaitu Ciherang dan Inpari 18. Kombinasi persilangan dari galur-galur yang diuji ialah CG-9 (INPAGO 8 x IR83140-B-11-B) sebanyak 16 galur, CG-10 (B1111430D-MR-1-PN-3-MR-2-Si-3-PN x B12825E-TB-1-25) sebanyak 1 galur, CG-11 (B1111430DMR-1-1-PN-3-MR-2-Si-3-PN x IR87705-14-11-B-SKI-12) sebanyak 3 galur, dan CG-12 (B1111430D-MR-1-1-PN-3MR-2-Si-3-PN x IR83140B-11-B) sebanyak 10 galur.

Rancangan yang digunakan adalah rancangan kelompok lengkap teracak (RKLT) satu faktor. Perlakuan yang digunakan adalah 30 galur dihaploid dan 2 varietas pembanding dengan 3 ulangan sehingga terdapat 96 satuan percobaan. Satu petak percobaan memiliki ukuran $1.5 \mathrm{~m}^{2}$. Persemaian dilakukan dengan sistem semai kering pada bak semai selama 18 hari. Pengolahan tanah dilakukan hingga terbentuk pelumpuran yang sempurna. Pengairan dilakukan secara optimum sesuai dengan pengairan pada padi sawah irigasi. Jarak tanam yang digunakan adalah $25 \mathrm{~cm}$ x $25 \mathrm{~cm}$ dengan 1 bibit per lubang. Pupuk yang diberikan adalah Urea $\left(200 \mathrm{~kg} \mathrm{ha}^{-1}\right)$, SP $36\left(100 \mathrm{~kg} \mathrm{ha}^{-1}\right)$, dan $\mathrm{KCl}(100 \mathrm{~kg}$ $\mathrm{ha}^{-1}$ ). Seluruh pupuk SP 36 dan $\mathrm{KCl}$ diberikan pada 1 minggu setelah tanam (MST). Pupuk Urea diberikan pada $1 \mathrm{MST}, 4 \mathrm{MST}$, dan 7 MST dengan dosis masing-masing $1 / 3$ dari dosis total. Padi dipanen ditandai dengan $90 \%$ bulir padi telah menguning.

Pengamatan karakter agronomi dilakukan terhadap tinggi tanaman, jumlah anakan produktif, umur panen, panjang malai, jumlah gabah isi per malai, jumlah gabah hampa per malai, jumlah gabah total per malai, bobot 1,000 butir, dan produktivitas. Analisis data yang dilakukan adalah perhitungan nilai heritabilitas arti luas, koefisien keragaman genetik (KKG) (Singh dan Chaudary, 1979), analisis korelasi Pearson, analisis sidik lintas, dan analisis komponen utama.

Penentuan luas atau sempitnya keragaman genetik ditentukan berdasarkan ragam genetik dan standar deviasi ragam genetik (Pinaria et al., 1995) yaitu:

$\mathrm{h}_{\mathrm{bs}}^{2}=\frac{\sigma_{\mathrm{g}}^{2}}{\sigma_{\mathrm{p}}^{2}} ; \quad \mathrm{KKG}=\frac{\sqrt{\sigma_{\mathrm{g}}^{2}}}{\bar{x}} ; \sigma \sigma_{\mathrm{g}}^{2}=\sqrt{\frac{2}{\mathrm{r}^{2}}}\left[\frac{\mathrm{M}_{2}^{2}}{\mathrm{db}_{\mathrm{g}}+2}+\frac{\mathrm{M}_{1}^{2}}{\mathrm{db}_{\mathrm{e}}+2}\right]$

(Keterangan: $\mathrm{h}_{\mathrm{bs}}^{2}$ : heritabilitas arti luas, $\sigma_{\mathrm{g}}^{2}$ : ragam genetik, $\sigma_{\mathrm{p}}^{2}$ : ragam fenotipik, KKG : koefisien keragaman genetik, $\sigma \sigma_{\mathrm{g}}^{2}$ : standar deviasi ragam genetik, $\mathrm{r}$ : jumlah ulangan, $\mathrm{M}_{1}=$ kuadrat tengah galat, $\mathrm{M}_{2}=$ kuadrat tengah genotipe, dbg: derajat bebas genotipe, dbe : derajat bebas galat, dimana: $\sigma_{\mathrm{g}}^{2}>2 \sigma \sigma_{\mathrm{g}}^{2}=$ keragaman genetik luas, $\sigma_{\mathrm{g}}^{2}<2 \sigma \sigma_{\mathrm{g}}^{2}$ $=$ keragaman genetik sempit).

Pengelompokan nilai heritabilitas arti luas menurut Stanfield (1983): tinggi $\left(0.50<\mathrm{h}^{2}{ }_{\mathrm{bs}}<1.00\right)$, sedang $(0.20<$ $\left.\mathrm{h}_{\mathrm{bs}}^{2}<0.50\right)$, dan rendah $\left(\mathrm{h}_{\mathrm{bs}}^{2}<0.20\right)$. Analisis data dilakukan menggunakan perangkat lunak Microsoft Excel 2013, STAR IRRI dan $\mathrm{R}$ versi 3.5.2 package factoextra untuk analisis komponen utama. 


\section{HASIL DAN PEMBAHASAN}

\section{Keragaan Karakter Agronomi Galur-galur Dihaploid Padi Sawah}

Nilai koefisien keragaman untuk setiap karakter agronomi berkisar antara 2.1-19.5\% (Tabel 1). Rata-rata tinggi tanaman sebesar $108.9 \mathrm{~cm}$ dengan kisaran antara 86.0-142.8 cm (Tabel 1). Menurut IRRI (2013), tinggi tanaman padi sawah dapat digolongkan menjadi tiga, yaitu pendek $(<110 \mathrm{~cm})$, sedang $(110-130 \mathrm{~cm})$, dan tinggi $(>130$ $\mathrm{cm})$. Berdasarkan pengelompokan tersebut sebanyak 20 galur kategori pendek, 6 galur kategori sedang, dan 4 galur kategori tinggi. Tanaman diharapkan memiliki tinggi yang sedang agar tidak mudah rebah ketika pengisian gabah sehingga daya hasil tetap tinggi. Galur kategori tersebut yaitu CG-9-26-1-5 (124.7 cm), CG-9-68-1-5 (121.0 cm), dan CG-12-85-1-3 (117.0 cm). Rata-rata jumlah anakan produktif sebesar 13.2 anakan dengan berkisar antara 9.3-18.3 anakan (Tabel 1). Menurut IRRI (2013), jumlah anakan produktif padi sawah dapat digolongkan menjadi lima, yaitu sangat sedikit ( $<5$ anakan), sedikit (5-9 anakan), sedang (10-19 anakan), ideal (20-25 anakan), dan sangat banyak ( $>25$ anakan). Dari hasil pengelompokan tersebut, semua galur yang diuji kategori sedang. Galur CG-9-27-1-1 (18.3 anakan), CG-9-53-1-1 (17.3 anakan), CG-11-69-1-2 (17 anakan) memiliki jumlah anakan berbeda nyata lebih banyak dibandingkan Inpari 18 (10.7 anakan).

Rata-rata umur panen sebesar 110.1 hari setelah semai dengan kisaran antara 107.0-119.0 hari (Tabel 1). Dewi et al. (2009) mengelompokkan umur panen (P) varietas padi menjadi empat yaitu sangat genjah ( $\mathrm{P} \leq 110 \mathrm{HSS})$, genjah (110 $<\mathrm{P} \leq 115$ HSS $)$, sedang (115 $<\mathrm{P} \leq 125 \mathrm{HSS})$, dan berumur dalam $(125<\mathrm{P} \leq 150 \mathrm{HSS})$. Galur CG-9-46-1-1 (107 hari), CG-9-68-1-3 (108 hari), dan CG-9-68-1-5 (108 hari) memiliki umur panen yang sangat genjah dan tidak berbeda nyata dengan Ciherang (109.7 hari) dan Inpari 18 (109.7 hari). Rata-rata panjang malai sebesar $25.7 \mathrm{~cm}$ dengan kisaran antara 21.7-29.7 cm (Tabel 1). Galur CG12-53-1-1 (28.6 cm), CG-12-71-1-1 (29.7 cm), dan CG$12-85-1-2(28.5 \mathrm{~cm})$ memiliki panjang malai berbeda nyata lebih panjang dibandingkan dengan varietas Ciherang (24.5 $\mathrm{cm})$ dan Inpari $18(21.7 \mathrm{~cm})$.

Rata-rata jumlah gabah isi per malai sebesar 113.4 butir dengan kisaran antara 56.4-165.0 butir (Tabel 1). Galur CG-12-30-1-3 (165 butir), CG-12-71-1-1 (149.1 butir), CG12-85-1-2 (148.6 butir) memiliki jumlah gabah isi per malai berbeda nyata lebih banyak dibandingkan dengan varietas Ciherang (89.8 butir) dan Inpari 18 (56.4 butir). Rata-rata jumlah gabah hampa per malai sebesar 68.1 butir dengan kisaran antara 31.4-134.0 butir (Tabel 1). Rata-rata jumlah gabah total per malai sebesar 181.4 butir berkisar antara 131.4-270.1 butir (Tabel 1). Galur CG-12-71-1-1 (270.1 butir), CG-12-85-1-2 (256.9 butir), CG-12-53-1-3 (238 butir) memiliki jumlah gabah total per malai berbeda nyata lebih banyak dibandingkan dengan varietas Ciherang (133.3 butir) dan Inpari 18 (118.5 butir). Rata-rata bobot 1,000 butir gabah bernas 23.5 g dengan kisaran 20.1-29.4 g (Tabel 1).
Bobot 1,000 butir gabah bernas pada umumnya berada pada kisaran 25-29 g (Abdullah et al., 2008). Galur CG-12-30-12 (28.4 g), CG-9-27-1-2 (27.3 g), dan CG-12-71-1-1 (27.0 g) termasuk dalam kategori ini. Rata-rata produktivitas galur dihaploid sebesar 4.1 ton ha ${ }^{-1}$ dengan kisaran 2.2-5.6 ton $\mathrm{ha}^{-1}$. Varietas Ciherang memiliki produktivitas sebesar 3.8 ton ha $^{-1}$. Galur CG-9-27-1-2 merupakan galur dengan produktivitas tertinggi sebesar 5.6 ton ha-1 . Galur CG-9-261-5 (5.1 ton ha ${ }^{-1}$ ), CG-9-27-1-2 (5.6 ton ha ${ }^{-1}$ ), CG-9-62-1-1 (5.4 ton ha ${ }^{-1}$ ), dan CG-12-85-1-2 (5.3 ton ha-1) merupakan galur-galur yang memiliki produktivitas lebih dari 5 ton $\mathrm{ha}^{-1}$.

Komponen Ragam dan Nilai Duga Heritabilitas Galur Dihaploid Padi Sawah

Semua karakter yang diamati memiliki keragaman genetik yang luas kecuali pada karakter daya hasil (Tabel 2). Galur-galur dihaploid yang digunakan memiliki tetua yang berbeda sehingga memiliki keragaman genetik yang luas. Nilai KKG karakter yang diamati berkisar 12.9-56.1\%. Karakter dengan nilai KKG tinggi, yaitu nilai yang lebih dari 20\% (Kumar et al., 2013) dapat dipilih untuk dijadikan kriteria seleksi. Keragaman genetik yang luas dapat disebabkan latar belakang genetik yang berbeda (Syukur et al., 2010). Seleksi dapat dilakukan secara efektif dengan adanya keragaman genetik yang luas. Seleksi dengan menggunakan nilai KKG yang tinggi dapat menyeleksi secara efektif galur padi dihaploid (Syafii et al., 2018; Akhmadi et al., 2017).

Nilai heritabilitas berada pada kisaran 0.23-0.97 (Tabel 2). Semua karakter memiliki heritabilitas tinggi kecuali karakter daya hasil yang memiliki kategori sedang. Nilai heritabilitas yang tinggi menunjukkan bahwa karakter tersebut dapat diwariskan karena dipengaruhi oleh faktor genetik. Nilai hertabilitas ini akan menentukan waktu seleksi yang tepat pada setiap karakter yang diamati pada generasi selanjutnya. Nilai heritabilitas yang rendah disebabkan karena pengaruh lingkungan yang tinggi. Nilai heritabilitas yang tinggi pada populasi menandakan faktor genetik berperan dalam pembentukan fenotipe sehingga berpeluang untuk diwariskan ke generasi selanjutnya (Sari et al., 2014). Galur-galur dihaploid dari hasil kultur antera memiliki sifat homozigos atau galur murni (Dewi dan Purwoko, 2012) sehingga faktor genetik akan memberikan pengaruh besar pada fenotipe.

Koefisien Korelasi dan Analisis SidikLintas Galur Dihaploid Padi Sawah

Analisis korelasi menunjukkan hubungan antar karakter yang diamati. Hasil analisis korelasi disajikan pada Tabel 3. Karakter tinggi tanaman $\left(r=0.53^{* *}\right)$ dan jumlah gabah isi per malai $(\mathrm{r}=0.34 * *)$ memiliki korelasi yang nyata dan positif dengan karakter produktivitas. Nilai koefisien korelasi positif yang nyata dapat digunakan sebagai karakter seleksi karena peningkatan nilai pada karakter yang berkorelasi positif akan meningkatkan nilai karakter hasil. 
Tabel 1. Karakter agronomi galur-galur dihaploid padi sawah tadah hujan dengan varietas pembanding

\begin{tabular}{|c|c|c|c|c|c|c|c|c|c|c|}
\hline No & Genotipe & TT & AP & UP & PM & GI & $\mathrm{GH}$ & GT & BSB & PRD \\
\hline 1 & CG-9-26-1-5 & 124.7 & 10.7 & 109.3 & 26.1 & 130.5 & 48.8 & 179.3 & 23.2 & 5.1 \\
\hline 2 & CG-9-26-1-6 & 109.7 & 11.7 & 108.3 & 25.5 & 115.4 & 51.9 & 167.3 & 21.5 & 5.0 \\
\hline 3 & CG-9-27-1-1 & 101.7 & 18.3 & 114.3 & 25.6 & 85.1 & 57.2 & 142.3 & 26.4 & 3.9 \\
\hline 4 & CG-9-27-1-2 & 105.3 & 15.0 & 114.3 & 26.6 & 130.8 & 64.3 & 195.1 & 27.3 & 5.6 \\
\hline 5 & CG-9-46-1-1 & 99.3 & 11.7 & 107.0 & 25.5 & 110.7 & 77.6 & 188.3 & 26.0 & 3.2 \\
\hline 6 & CG-9-53-1-1 & 86.4 & 17.3 & 108.3 & 23.5 & 104.3 & 38.5 & 142.9 & 24.4 & 3.4 \\
\hline 7 & CG-9-53-1-2 & 89.7 & 13.3 & 108.3 & 23.6 & 84.3 & 57.1 & 141.3 & 25.0 & 3.5 \\
\hline 8 & CG-9-53-1-3 & 86.0 & 14.0 & 109.0 & 23.3 & 106.4 & 31.4 & 137.8 & 26.3 & 3.0 \\
\hline 9 & CG-9-53-1-4 & 88.8 & 14.7 & 108.3 & 23.0 & 86.5 & 44.9 & 131.4 & 25.4 & 4.1 \\
\hline 10 & CG-9-62-1-1 & 129.7 & 13.3 & 108.7 & 26.0 & 114.6 & 78.4 & 193.0 & 25.6 & 5.4 \\
\hline 11 & CG-9-68-1-3 & 134.7 & 15.7 & 108.0 & 25.8 & 107.3 & 64.5 & 171.8 & 23.3 & 4.9 \\
\hline 12 & CG-9-68-1-4 & 130.0 & 14.0 & 108.3 & 26.1 & 107.4 & 53.3 & 160.8 & 23.0 & 4.2 \\
\hline 13 & CG-9-68-1-5 & 121.0 & 15.0 & 108.0 & 26.1 & 106.8 & 58.6 & 165.3 & 25.1 & 4.2 \\
\hline 14 & CG-9-81-1-1 & 141.5 & 11.0 & 109.3 & 28.3 & 145.1 & 41.1 & 186.2 & 25.8 & 5.4 \\
\hline 15 & CG-9-81-1-2 & 142.8 & 13.3 & 108.7 & 28.3 & 144.2 & 54.8 & 199.0 & 24.0 & 3.9 \\
\hline 16 & CG-9-107-1-1 & 97.7 & 9.3 & 109.0 & 24.4 & 82.6 & 50.8 & 133.4 & 26.2 & 4.2 \\
\hline 17 & CG-10-78-1-1 & 93.3 & 10.3 & 108.3 & 22.0 & 73.8 & 65.3 & 139.1 & 25.5 & 4.5 \\
\hline 18 & CG-11-35-1-1 & 101.7 & 16.7 & 118.0 & 27.7 & 96.6 & 65.5 & 162.0 & 23.6 & 4.5 \\
\hline 19 & CG-11-69-1-1 & 105.3 & 13.7 & 111.3 & 27.8 & 125.8 & 71.8 & 197.6 & 24.9 & 4.6 \\
\hline 20 & CG-11-69-1-2 & 103.3 & 17.0 & 115.0 & 28.4 & 108.1 & 83.9 & 192.0 & 25.4 & 3.8 \\
\hline 21 & CG-12-30-1-2 & 109.8 & 12.0 & 108.0 & 23.4 & 136.0 & 62.1 & 198.1 & 28.4 & 4.4 \\
\hline 22 & CG-12-30-1-3 & 100.0 & 9.3 & 108.7 & 24.0 & 165.0 & 57.6 & 222.6 & 24.9 & 3.8 \\
\hline 23 & CG-12-30-2-1 & 101.3 & 11.0 & 108.7 & 22.7 & 137.9 & 50.1 & 188.0 & 25.2 & 4.9 \\
\hline 24 & CG-12-53-1-1 & 103.0 & 11.7 & 114.3 & 28.6 & 80.1 & 134.0 & 214.0 & 24.8 & 2.2 \\
\hline 25 & CG-12-53-1-3 & 100.3 & 13.7 & 119.0 & 27.8 & 144.0 & 94.0 & 238.0 & 22.0 & 2.3 \\
\hline 26 & CG-12-58-1-1 & 110.0 & 9.7 & 108.3 & 23.8 & 137.5 & 88.6 & 226.1 & 24.0 & 3.8 \\
\hline 27 & CG-12-71-1-1 & 127.0 & 12.0 & 111.3 & 29.7 & 149.1 & 121.0 & 270.1 & 27.0 & 4.4 \\
\hline 28 & CG-12-73-1-1 & 100.7 & 13.7 & 108.7 & 25.6 & 101.2 & 85.7 & 186.9 & 22.7 & 3.7 \\
\hline 29 & CG-12-85-1-2 & 127.3 & 13.3 & 108.3 & 28.5 & 148.6 & 108.4 & 256.9 & 24.7 & 5.3 \\
\hline 30 & CG-12-85-1-3 & 117.0 & 14.0 & 109.3 & 27.4 & 115.8 & 111.9 & 227.7 & 26.1 & 3.7 \\
\hline 31 & Ciherang & 107.3 & 16.3 & 109.7 & 24.5 & 89.8 & 43.5 & 133.3 & 25.5 & 3.8 \\
\hline \multirow[t]{7}{*}{32} & Inpari 18 & 87.2 & 10.7 & 109.7 & 21.7 & 56.4 & 62.1 & 118.5 & 29.9 & 3.0 \\
\hline & Rata-rata & 108.9 & 13.2 & 110.1 & 25.7 & 113.4 & 68.1 & 181.4 & 23.5 & 4.1 \\
\hline & Maksimum & 142.8 & 18.3 & 119.0 & 29.7 & 165.0 & 134.0 & 270.1 & 29.4 & 5.6 \\
\hline & Minimum & 86.0 & 9.3 & 107.0 & 21.7 & 56.4 & 31.4 & 118.5 & 20.1 & 2.2 \\
\hline & KK $(\%)$ & 4.4 & 19.5 & 2.1 & 4.1 & 12.5 & $17.4^{\#}$ & 15.8 & 6.4 & $4.1^{\#}$ \\
\hline & Genotipe & $* *$ & $* *$ & $* *$ & $* *$ & $* *$ & $* *$ & $* *$ & $* *$ & tn \\
\hline & BNT 5\% & 7.8 & 4.2 & 3.8 & 1.7 & 45.6 & 36.4 & 47.2 & 2.6 & - \\
\hline
\end{tabular}

Keterangan: $\mathrm{TT}=$ tinggi $\operatorname{tanaman}(\mathrm{cm}) ; \mathrm{AP}=$ anakan produktif per rumpun; $\mathrm{UP}=$ umur panen (hari); $\mathrm{PM}=$ panjang malai $(\mathrm{cm}) ; \mathrm{GI}=$ jumlah gabah isi per malai; $\mathrm{GH}=$ jumlah gabah hampa per malai; $\mathrm{GT}=$ jumlah gabah total per malai; $\mathrm{BSB}=$ bobot gabah 1,000 butir (g); PRD = produktivitas (ton ha $\left.{ }^{-1}\right) ; \mathrm{KK}=$ koefisien keragaman; ** = berbeda nyata pada $\alpha 0.01 ; *=$ berbeda nyata pada $\alpha$ $0.05 ; \mathrm{tn}=$ tidak berbeda nyata pada $\alpha 0.05$; \# Data ditransformasi dengan rumus $(\mathrm{x}+0.5)^{0.5}$ 
Tabel 2. Komponen ragam dan nilai duga heritabilitas arti luas karakter agronomi galur-galur dihaploid padi sawah tadah hujan

\begin{tabular}{|c|c|c|c|c|c|c|c|}
\hline \multirow{2}{*}{ Karakter } & \multirow{2}{*}{$\sigma_{\mathrm{g}}^{2}$} & \multirow{2}{*}{$\sigma_{\mathrm{p}}^{2}$} & \multirow{2}{*}{$\begin{array}{c}\text { KKG } \\
(\%)\end{array}$} & \multirow{2}{*}{$2 \sigma \sigma_{\mathrm{g}}^{2}$} & \multirow{2}{*}{$\begin{array}{c}\text { Kriteria } \\
\mathrm{KKG}\end{array}$} & \multicolumn{2}{|c|}{$\mathrm{h}_{\mathrm{bs}}^{2}$} \\
\hline & & & & & & Nilai & Kriteria \\
\hline Tinggi tanaman $(\mathrm{cm})$ & 253.4 & 261.2 & 38.2 & 132.7 & Luas & 0.97 & Tinggi \\
\hline Anakan produktif & 3.6 & 5.8 & 37.8 & 3.1 & Luas & 0.62 & Tinggi \\
\hline Umur panen (hari) & 7.4 & 9.2 & 15.7 & 4.7 & Luas & 0.81 & Tinggi \\
\hline Panjang malai (cm) & 4.3 & 4.7 & 28.5 & 2.4 & Luas & 0.92 & Tinggi \\
\hline Jumlah gabah isi & 433.6 & 692.2 & 42.9 & 364.1 & Luas & 0.63 & Tinggi \\
\hline Jumlah gabah hampa & 460.1 & 625.4 & 56.1 & 323.4 & Luas & 0.74 & Tinggi \\
\hline Jumlah gabah total & $1,195.7$ & $1,472.4$ & 43.7 & 754.8 & Luas & 0.81 & Tinggi \\
\hline Bobot seribu butir (g) & 2.2 & 3.0 & 20.5 & 1.6 & Luas & 0.72 & Tinggi \\
\hline Produktivitas (ton ha-1) & 0.2 & 0.7 & 12.9 & 0.4 & Sempit & 0.23 & Sedang \\
\hline
\end{tabular}

Keterangan: $\mathrm{KKG}=$ koefisien keragaman genetik; $2 \sigma \sigma_{\mathrm{g}}^{2}=2 \mathrm{x}$ standar deviasi ragam genetik; $\mathrm{h}_{\mathrm{bs}}^{2}=$ heritabilitas arti luas

Tabel 3. Nilai koefisien korelasi antar karakter agronomi galur-galur dihaploid padi sawah tadah hujan

\begin{tabular}{lllllllll}
\hline & TT & AP & UP & PM & GI & GH & GT & BSB \\
\hline AP & -0.04 & & & & & & & \\
UP & -0.15 & $0.38^{*}$ & & & & & & \\
PM & $0.60^{* *}$ & 0.23 & $0.47^{* *}$ & & & & & \\
GI & $0.51^{* *}$ & -0.23 & -0.01 & $0.41^{*}$ & & & & \\
GH & 0.17 & -0.10 & 0.32 & $0.57^{* *}$ & 0.15 & & & \\
GT & $0.45^{* *}$ & -0.22 & 0.19 & $0.64^{* *}$ & $0.77^{* *}$ & $0.74^{* *}$ & & \\
BSB & 0.09 & -0.22 & 0.02 & -0.01 & -0.04 & 0.12 & 0.05 & \\
PRD & $0.53^{* *}$ & -0.05 & -0.24 & 0.13 & $0.34^{* *}$ & -0.22 & 0.09 & -0.07 \\
\hline
\end{tabular}

Keterangan: $\mathrm{TT}=$ tinggi tanaman $(\mathrm{cm}) ; \mathrm{AP}=$ anakan produktif per rumpun; $\mathrm{UP}=$ umur panen (hari); $\mathrm{PM}=$ panjang malai $(\mathrm{cm})$; $\mathrm{GI}=$ jumlah gabah isi per malai; $\mathrm{GH}=$ jumlah gabah hampa per malai; $\mathrm{GT}=$ jumlah gabah total per malai; $\mathrm{BSB}=$ bobot gabah 1,000 butir (g); PRD = produktivitas $\left(\right.$ ton ha $\left.\mathrm{a}^{-1}\right)$

Nilai koefisien korelasi yang nyata dan positif antara daya hasil dengan tinggi tanaman juga didapatkan oleh Kole et al. (2011) dan jumlah gabah isi didapatkan oleh Seyoum et al. (2012); Akinwale et al. (2011).

Karakter yang memiliki nilai pengaruh langsung terhadap hasil ialah tinggi tanaman dan jumlah gabah isi per malai (Tabel 4). Karakter yang memiliki nilai pengaruh tidak langsung terhadap hasil ialah panjang malai, jumlah gabah isi per malai, dan jumlah gabah total per malai (Tabel 4). Karakter seleksi yang baik adalah yang memiliki nilai korelasi nyata yang tinggi dan nilai pengaruh langsung atau nilai pengaruh tidak langsung terhadap hasil yang tinggi (Boer, 2011). Karakter daya hasil dilaporkan memiliki pengaruh langsung terhadap tinggi tanaman oleh Kole et al. (2008) dan jumlah gabah isi per malai oleh Sadeghi (2011).

\section{Penentuan Karakter Seleksi Galur Dihaploid Padi Sawah}

Pemilihan karakter seleksi pada galur-galur yang diuji berdasarkan beberapa kriteria yaitu memiliki keragaman genetik yang luas, nilai heritabilitas yang tinggi, memiliki korelasi yang positif, dan berpengaruh langsung terhadap terhadap karakter produksi. Berdasarkan kriteria tersebut didapatkan bahwa karakter tinggi tanaman dan jumlah gabah isi per malai dapat dijadikan sebagai karakter penunjang produksi. Pemuliaan padi galur dihaploid padi sawah diarahkan untuk mencapai daya hasil yang tinggi (Akbar et al., 2018b) sehingga karakter daya hasil menjadi karakter utama dalam seleksi.

Hubungan antara karakter produktivitas, tinggi tanaman, dan jumlah gabah isi per malai dapat dilihat dengan analisis komponen utama (AKU). Analisis KU dapat dijadikan sebagai indeks seleksi dengan pembobotan berdasarkan nilai KU setiap karakter. Analisis KU menunjukkan bahwa total keragaman dari tiga KU pertama sebesar $72.83 \%$. Kontribusi keragaman masing-masing pada tiga komponen utama yaitu KU 1 (35.5\%), KU 2 (21.4\%), KU 3 (16.0\%) (Tabel 5). KU 2 menunjukkan bahwa nilai KU karakter produktivitas (0.48) lebih besar dibandingkan dengan nilai KU tinggi tanaman (0.31) dan 
Tabel 4. Koefisien sidik lintas karakter agronomi terhadap hasil pada galur-galur dihaploid padi sawah tadah hujan

\begin{tabular}{|c|c|c|c|c|c|c|c|c|c|c|}
\hline \multirow{2}{*}{ Karakter } & \multirow{2}{*}{$\begin{array}{l}\text { Pengaruh } \\
\text { langsung }\end{array}$} & \multicolumn{8}{|c|}{ Pengaruh tidak langsung } & \multirow{2}{*}{ Total } \\
\hline & & TT & AP & UP & PM & GI & $\mathrm{GH}$ & GT & BSB & \\
\hline TT & 0.66 & & 0.00 & -0.01 & -0.13 & 0.08 & -0.03 & -0.03 & -0.01 & -0.13 \\
\hline AP & -0.02 & -0.03 & & 0.02 & -0.05 & -0.04 & 0.02 & 0.02 & 0.03 & -0.03 \\
\hline UP & 0.05 & -0.11 & -0.01 & & -0.10 & 0.00 & -0.06 & -0.01 & 0.00 & -0.29 \\
\hline PM & -0.21 & 0.4 & -0.01 & 0.03 & & 0.07 & -0.11 & -0.05 & 0.00 & 0.34 \\
\hline GI & 0.16 & 0.34 & 0.01 & 0.00 & -0.09 & & -0.03 & -0.06 & 0.01 & 0.18 \\
\hline GH & -0.19 & 0.11 & 0.00 & 0.02 & -0.12 & 0.02 & & -0.06 & -0.02 & -0.03 \\
\hline GT & -0.07 & 0.3 & 0.00 & 0.01 & -0.13 & 0.12 & -0.14 & & -0.01 & 0.16 \\
\hline BSB & -0.12 & 0.07 & 0.01 & 0.00 & 0.00 & -0.01 & -0.02 & 0.00 & & 0.04 \\
\hline
\end{tabular}

Keterangan: $\mathrm{TT}=$ tinggi tanaman $(\mathrm{cm}) ; \mathrm{AP}=$ anakan produktif per rumpun; $\mathrm{UP}=$ umur panen $($ hari $) ; \mathrm{PM}=$ panjang malai $(\mathrm{cm}) ; \mathrm{GI}=$ jumlah gabah isi per malai; $\mathrm{GH}=$ jumlah gabah hampa per malai; $\mathrm{GT}=$ jumlah gabah total per malai; $\mathrm{BSB}=$ bobot gabah 1,000 butir $(\mathrm{g})$

jumlah gabah isi per malai (0.27). Nilai negatif pada KU hanya menunjukkan posisi absolut dari arah keragaman karakter sehingga nilai koefisien tersebut dapat digunakan sebagai pembobot dalam indeks tanpa memperhatikan tanda negatifnya. Produktivitas memiliki pembobotan lebih besar dibandingkan karakter lainnya. Jumlah gabah isi per malai diharapkan meningkat seiring dengan peningkatan produktivitas. Tinggi tanaman memiliki nilai negatif karena diharapkan galur yang terseleksi nantinya merupakan galurgalur yang memiliki tinggi yang sedang. Berdasarkan hal tersebut didapatkan suatu model yaitu Indeks seleksi $=0.48$ PRD + 0.31 GI - 0.31 TT. Model tersebut dapat digunakan dalam melakukan selaksi secara objektif pada galur-galur dihaploid padi sawah yang diuji.

Tabel 5. Analisis komponen utama agronomi galur-galur dihaploid padi sawah tadah hujan

\begin{tabular}{lccccc}
\hline Karakter & KU 1 & KU 2 & KU 3 & KU 4 & KU 5 \\
\hline Tinggi tanaman (cm) & -0.39 & -0.31 & 0.21 & -0.31 & 0.33 \\
Anakan produktif & 0.05 & 0.34 & 0.63 & -0.18 & 0.08 \\
Umur panen (hari) & -0.14 & 0.56 & 0.17 & -0.12 & -0.53 \\
Panjang malai (cm) & -0.47 & 0.22 & 0.23 & -0.14 & 0.16 \\
Jumlah gabah isi & -0.42 & -0.27 & 0.00 & 0.26 & -0.55 \\
Jumlah gabah hampa & -0.37 & 0.34 & -0.31 & 0.09 & 0.46 \\
Jumlah gabah total & -0.52 & 0.04 & -0.20 & 0.23 & -0.08 \\
Bobot seribu butir (g) & -0.04 & 0.00 & -0.46 & -0.82 & -0.21 \\
Produktivitas (ton ha $\left.{ }^{-1}\right)$ & -0.15 & -0.48 & 0.37 & -0.20 & -0.09 \\
\hline Nilai eigen & 3.19 & 1.92 & 1.44 & 0.96 & 0.61 \\
Keragaman (\%) & 35.5 & 21.38 & 15.96 & 10.61 & 6.74 \\
Akumulasi (\%) & 35.5 & 56.88 & 72.83 & 83.45 & 90.19 \\
\hline
\end{tabular}

\section{KESIMPULAN}

Penentuan karakter seleksi didapatkan bahwa karakter tinggi tanaman, jumlah gabah isi per malai, dan produktivitas dapat dijadikan sebagai karakter seleksi untuk padi sawah tadah hujan berdaya hasil tinggi. Model yang diperoleh yaitu Indeks seleksi $=0.48 \mathrm{PRD}+0.31 \mathrm{JGI}-0.31 \mathrm{TT}$. Model tersebut dapat digunakan dalam melakukan seleksi pada galur-galur dihaploid padi sawah berdaya hasil tinggi.

\section{UCAPAN TERIMAKASIH}

Ucapan terimakasih disampaikan kepada Kementerian Riset, Teknologi, dan Pendidikan Tinggi, Republik Indonesia yang telah mendanai penelitian ini melalui skema hibah penelitian PMDSU tahun anggaran 2016. 


\section{DAFTAR PUSTAKA}

Abdi, H., L.J. Williams. 2010. Principal component analysis. Wiley Interdisciplinary Reviews: Computational Statistics 2:433-459.

Abdullah, B., I.S. Dewi, Sularjo, H. Safitri, A.P. Lestari. 2008. Perakitan padi tipe baru melalui seleksi silang berulang dan kultur anter. J. Penel. Pertan. Tan. Pangan 27:1-8.

Akbar, M.R., B.S. Purwoko, I.S. Dewi, W.B. Suwarno. 2018a. Penentuan indeks seleksi toleransi kekeringan galur dihaploid padi sawah tadah hujan pada fase perkecambahan. J. Agron. Indonesia 46:133-139.

Akbar, M.R., B.S. Purwoko, I.S. Dewi, W.B. Suwarno, Sugiyanta. 2018b. Agronomic and drought tolerance evaluation of doubled haploid rice breeding lines derived from anther culture. SABRAO J. Breed. Genet. 50:115-128.

Akhmadi, G., B.S. Purwoko, I.S. Dewi, D. Wirnas, 2017. Pemilihan karakter agronomi untuk seleksi pada galur-galur padi dihaploid hasil kultur antera. J. Agron. Indonesia 45:1-8.

Akinwale, M.G., G. Gregorio, F. Nwilene, B.O. Akinyele, S.A. Ogunbayo, A.C. Odiyi. 2011. Heritability and correlation coefficient analysis for yield and its components in rice (Oryza sativa L.). AJPS. 5:207212.

[BPS] Badan Pusat Statistik. 2018. Luas Panen dan Produksi Padi di Indonesia 2018. http://www.bps.go.id/ [19 Februari 2019].

Boer, D. 2011. Analisis variabilitas genetik dan koefisien lintas berbagai karakter agronomi dan fisiologi terhadap hasil biji dari keragaman genetik 54 asesi jagung asal Indonesia timur. Agroteksos. 135-43.

Dewi, I.S., B.S. Purwoko. 2012. Kultur antera untuk percepatan perakitan varietas padi di Indonesia. J. AgroBiogen 8:78-88.

Dewi, I.S., A.C. Trilaksana, Trikosoemaningtyas, B.S. Purwoko. 2009. Karakterisasi galur haploid ganda hasil kultur antera. Bul. Plasma Nutfah 15:1-12.

Gunarsih, C., B.S. Purwoko, I.S. Dewi, M. Syukur. 2016. Regenerasi dan aklimatisasi kultur antera enam persilangan F1 padi sawah. J. Agron. Indonesia 22:133-140.

[IRRI] International Rice Research Institute. 2013. Standard Evaluation System for Rice. INGER-IRRI, Manila, PH.
Islam, M.R., M.O. Kayess, M. Hasanuzzaman, M.W. Rahman, M.J. Uddin, M.R. Zaman. 2017. Selection index for genetic improvement of wheat (Triticum aestivum L.). JCBPS. 7:1-8.

Janmohammadi, M., Z. Movehedi, N. Sabaghnia. 2014. Multivariate statistical analysis of some traits of bread wheat for breeding under rainfed conditions. J. Agric. Sci. 59:1-13.

[Kementan] Kementerian Pertanian. 2018. Statistik Pertanian 2018. Pusat Data dan Sistem Informasi Pertanian-Kementerian Pertanian, Jakarta, ID.

Kole, P.C., N.R. Chakraborty, J.S. Bhat. 2008. Analysis of variability, correlation and path coefficients in induced mutants of aromatic non-basmati rice. Trop. Agric. Res. Ext. 11:60-64.

Kumar, S.R., T. Arumugam, S. Balakrishnan, C.R. Anandakumar. 2013. Variability in the segregating generation of eggplant for earliness and yield. Pak. J. Biol. Sci. 16:1122-1129.

Nachimuthu, V.V., S. Robin, D. Sudhakar, M. Raveendran, S. Rajeswari, S. Manonmani. 2014. Evaluation of rice genetic diversity and variability in a population panel by principal component analysis. Indian J. Sci Technol. 7:1555-1562.

Pinaria,A.,A.Baihaki, R. Setiamihardja,A.A.Daradjat. 1995. Variabilitas genetik dan heritabilitas karakterkarakter biomassa 53 genotipe kedelai. Zuriat 6:88-92.

Purwoko, B.S., I.S. Dewi, N. Khumaida. 2010. Rice anther culture to obtain doubled-haploids with multiple tolerances. Asia Pacific J. Mol. Biol. Biotechnol. 18:55-57.

Sadeghi, S.M. 2011. Heritability, phenotypic correlation, and path coefficient studies for some agronomic characters in landrace rice varieties. World Appl. Sci. J. 13:1229-1233.

Safitri, H., B.S. Purwoko, D. Wirnas, I.S. Dewi, B. Abdullah. 2010. Daya kultur antera beberapa persilangan padi gogo dan padi tipe baru. J. Agron. Indonesia 38:8187.

Sari, W.P., Damanhuri, Respatijarti. 2014. Keragaman dan heritabilitas 10 genotipe pada cabai besar (Capsicum anuum L.). Produksi Tanaman 2:301-307.

Seyoum, M., S. Alamerew, K. Bantte. 2012. Genetic variability, heritability, coefficient and path analysis for yield and yield related traits in upland rice (Oryza sativa L.). J. Plant Sci. 7:13-22. 
Singh, R.K., B.D. Chaudhary. 1979. Biometrical Methods in Quantitative Genetic Analysis. Kalyani Publisher. New Delhi, IN.

Stanfield, W.D. 1983. Theory and Problems of Genetics, 2nd edition. Schain's Outline Series. Mc. Graw-Hill. New Delhi, IN.

Syafii, M., B.S. Purwoko, I.S. Dewi, W.B. Suwarno. 2018. Karakter agronomi galur padi dihaploid asal kultur antera hasil persilangan three way cross. J. Agron. Indonesia 46:9-16.

Syukur, M., S. Sujiprihati, R. Yunianti, K. Nida. 2010. Pendugaan komponen ragam, heritabilitas dan korelasi untuk menentukan kriteria seleksi cabai (Capsicum annuum L.) populasi F5. J. Hort. Indonesia 1:74-80.

Susanto, U., A. Imamudiin, M.Y. Samaullah, S. Satoto, A. Jamil, J. Ali. 2017. Keragaan galur-galur green super rice pada kondisi sawah tadah hujan saat musim kemarau di Kabupaten Pati. Bul. Plasma Nutfah 23:41-50.

Yunianti, R., S. Sastrosumarjo, S. Sujiprihati, M. Surahman, S.H. Hidayat. 2010. Kriteria seleksi untuk perakitan varietas cabai tahan Phytophthora capsici Leonian. J. Agron. Indonesia 38:122-129. 